\title{
O PROJETO EDUCAÇÃO 2030 DA OCDE: uma bússola para a aprendizagem
}

\author{
Maria Abádia da Silva \\ Edison Flávio Fernandes²
}

\section{RESUMO}

O presente artigo analisa o projeto Education 2030: The Future of Education and Skills, instituído pela OCDE em 2015 e que propõe uma matriz conceitual de aprendizagem e a criação e condução de um currículo internacional formado a partir de uma bússola de aprendizagem. Tal concepção entrelaça novas competências (conhecimentos, habilidades, atitudes e valores) a serem inseridas nos currículos escolares dos países. Aponta as formas de atuação da OCDE na área educacional, os elementos visíveis e invisíveis do projeto e como a Educação Básica torna-se um nicho estratégico de exploração econômica e tecnológica. Ofusca-se, assim, o princípio da educação como um direito social e subjetivo, deslocando-se e favorecendo-se sua oferta como um serviço público consoante às regras de livre mercado.

Palavras-chave: OCDE e Educação Básica. Currículo Escolar. Competências e Habilidades.

\section{THE OECD'S EDUCATION 2030 PROJECT: a learning compass}

\begin{abstract}
The present paper analyzes the project entitled Education 2030: The Future of Education and Skills, established by the OECD in 2015, and which proposes the conception of a learning framework and the creation and conduction of an international curriculum formed from a learning compass. This conception resulted from the interweaving of new competences (knowledge, skills, attitudes and values) to be inserted in school curriculums worldwide. It points out the OECD's ways of acting, the visible and invisible elements of the project, and how basic education becomes a strategic niche for economic and technological exploitation. Thus, it obscures the
\end{abstract}

\footnotetext{
1 Doutora (1999) em Educação pela Universidade Estadual de Campinas (UNICAMP) São Paulo, Brasil. Professora do curso de Graduação em Pedagogia e do Programa de PósGraduação em Educação da Faculdade de Educação Universidade de Brasília (UnB/Brasilia/Brasil). Orcid iD: http://orcid.org/0000.0001.6048-077X. E-mail: abadiaunb@gmail.com

2 Mestre em Educação pela Universidade de Brasília (UnB/Brasília/Brasil). Orcid iD: http://orcid.org/0000.0001.7498-6210. E-mail: ediffer@gmail.com
} 
principle of education as a social and subjective right, displaces and favors its offer as a public service according to free market rules.

Keywords: OECD and Education Basic. Curriculum. Competences and Skills.

\section{EL PROYECTO EDUCACIÓN 2030 DE LA OCDE: una brújula para la aprendizaje}

\section{RESUMEN}

El presente artículo analiza el proyecto Education 2030: The Future of Education and Skills, instituido por la OCDE en 2015 y que propone una matriz conceptual de aprendizaje y la creación y conducción de un currículo internacional formado a partir de una brújula de aprendizaje. Tal concepción entrelaza nuevas competencias (conocimiento, habilidades, actitudes y valores) a seren insertadas en los currículos escolares de los países. Apunta las formas de actuación de la OCDE en el área educativa, los elementos visibles e invisibles del proyecto y cómo la educación básica se convierte en un nicho estratégico de explotación económica y tecnológica. Se ofusca, así, el principio de la educación como un derecho social y subjetivo, desplazándose y favoreciendo su oferta como un servicio público según las reglas de libre mercado.

Palabras clave: OCDE y Educación Básica. Currículo Escolar. Competencias y Habilidades.

\section{INTRODUÇÃO}

Em 2015, a Organização para Cooperação e Desenvolvimento Econômico (OCDE), por meio da Diretoria de Educação e Habilidades (EDU), iniciou discussões sobre um projeto para a definição internacional de quais conhecimentos, competências, habilidades, atitudes e valores os estudantes precisariam dominar para "prosperar e moldar as suas vidas e o mundo em 2030" (OCDE, s.d., p. 01, tradução nossa). O projeto Educação 2030: o Futuro da Educação e das Habilidades conta com a participação de representantes de países, instituições, empresários e organismos multilaterais, e prenuncia reorganizar políticas para a Educação Básica com foco na reestruturação de matrizes curriculares, a serem observadas pelos sistemas nacionais de ensino.

A OCDE é uma organização internacional criada em 1961, com sede em Paris e composta de 36 países membros. Possui como objetivo promover políticas que visem a manter a estabilidade financeira mundial, atuar em favor das leis de livre mercado, favorecer o crescimento econômico e servir 
de fórum em favor dos interesses e dos negócios comerciais entre paísesmembros. Sucedeu a Organização para a Cooperação Económica Europeia (OECE), criada em 16 de abril de 1948, para gerir o Plano Marshall na reconstrução europeia do pós II Guerra Mundial. Além dos 36 países membros da OCDE, há 13 países, incluindo Brasil, que não são membros, mas por subscreverem a Declaração de Investimentos da OCDE, possuem em seus territórios os chamados Pontos de Contato Nacional (PCN).

O Brasil estabelece cooperações com essa organização desde 1997 e em 2003 foi criado o Ponto de Contato Nacional (PCN/OCDE) em território nacional (BRASIL, 2003). Assim, a Portaria Interministerial $n^{\circ} 37 / 2013$ disciplina a estrutura e organização do PCN com as proposituras da OCDE para as Empresas Multinacionais (BRASIL, 2013).

Desde 1990, a OCDE vem ampliando sua atuação global na seara da educação. Suas decisões vão muito além do recorte pedagógico, atingindo esferas de interesses e poder, com influência e relações de forças não apenas nacionais, mas também globais. Atualmente é reconhecida pelos países-membros como um fórum que cria, propõe e dissemina tendências internacionais em educação por meio de diversos mecanismos de disseminação: indicadores, publicações, relatórios, testes e exames, estudos comparativos, além de ações diretas no governo de países-membros e parceiros-chave. A partir de maio de 2007, a Resolução do Conselho da OCDE sobre o Alargamento e o Envolvimento Reforçado, considera África do Sul, China, Índia, Indonésia e o Brasil parceiros-chave (key partners). Tal movimento visa à progressiva adesão dos países às instâncias da organização internacional, aos seus instrumentos legais (acquis), aos sistemas estatísticos e de elaboração de relatórios e às suas revisões por pares de setores específicos de políticas públicas.

As prescrições e programas educacionais da OCDE geram impactos na política de Educação Básica dos países, visto que suas proposições são traduzidas e replicadas em discursos públicos, legislação, planos e ações na Educação Básica pública. Elas afetam as maneiras pelas quais decisões econômicas, jurídicas e políticas são tomadas. Mais que isto, edificam um 
discurso com vocabulário próprio, de alcance global sobre os países, por intermédio da disseminação massiva de estudos, projetos e programas nas mais variadas áreas de políticas públicas. Neste movimento dinâmico e complexo, a organização suscita imprecisão entre os termos público e privado na educação, ofusca a distinção entre educação como direito social e subjetivo e educação como serviço público oferecido por reformadores empresariais. É dizer: discursos e vocabulários hegemônicos de alcance global servem como recursos legitimadores de ações e políticas locais, que tornam a educação e a escola uma commodity comercializável (SAVAGE, 2017).

Nesse complexo contexto econômico e tecnológico de reprodução do capital em escala ampliada, a OCDE adquiriu relevo na área de políticas para a Educação Básica. Nesse movimento na esfera educacional, o governo federal brasileiro tem participado, desde 1997, do Programa Internacional para Avaliação de Estudantes - PISA; desde 2008 da Pesquisa Internacional sobre Ensino e Aprendizagem - TALIS; e desde 2006 do programa Indicadores dos Sistemas Educacionais - INES, com ressonância variável nos processos nacionais de formulação de políticas públicas de Educação Básica.

Em 2015, a OCDE, por meio da Diretoria de Educação e Habilidades, propôs o Projeto Educação 2030 e compôs um movimento orgânico com representantes de países, instituições, stakeholders, experts, governos e empresários, almejando chegar a um consenso quanto aos elementos curriculares essenciais que as nações deveriam levar em consideração para preparar seus jovens para o trabalho e para a vida, antecipando-se às necessidades socioeconômicas de 2030. No horizonte político e econômico, indaga: que competências e habilidades serão exigidas em 2030 de uma criança que acabou de entrar no sistema educativo em 2015 ?

Neste empreendimento, relatórios comparativos, indicadores estatísticos, publicações com termos técnicos, metodológicos e políticos romperam as fronteiras do Centro de Convenções de Paris, sede da OCDE, e chegaram aos gabinetes dos governos e Secretarias de Educação dos paísesmembros e parceiros-chave. Este movimento gradual, mas contínuo e 
intencional, tem induzido reformas, mudanças nas leis, programas e projetos com anuência dos governos nacionais.

Mas, como aproximar países com realidades econômicas, sociais e educacionais tão díspares? Como entender os elementos que estão invisíveis na homogeneidade curricular internacional? A quem cabe definir a relevância social dos conteúdos de ensino para que se aprenda a pensar e a se objetivar no meio e no contexto em que se vive? Se os países possuem realidades históricas e determinantes econômicos distintos, que grupos estão interessados na definição e priorização de conteúdos globais comuns?

Estas indagações direcionam a trajetória investigativa deste artigo, no sentido de desvelar o núcleo do documento The Future of Education and Skills - Education 2030, também publicado sob o título E2030 Position Paper (OCDE, 2018a). Busca-se analisar sua gênese, dinâmica de construção ${ }^{3}$ e os elementos constituintes em âmbito internacional. Parte-se, deste modo, da expressão fenomênica para saturá-la de determinações; buscam-se seus elementos visíveis, invisíveis e conexões para, mediante esforço teórico e didático entrelaçado, apreender, no movimento real, as finalidades dessa política para a Educação Básica. Para tanto, o artigo compreende três seções: na primeira, apresenta-se o Projeto Educação 2030; na segunda, explicita-se a bússola da aprendizagem e os interesses políticos e econômicos subjacentes ao projeto; na terceira, evidenciam-se algumas conexões entre as proposições externas e sua tradução na política de Educação Básica como se fossem necessidades nacionais. Passemos à reflexão!

\section{O PROJETO EDUCAÇÃO 2030 DA OCDE: UM CURRÍCULO PARA O MUNDO}

Em 2015, a Diretoria de Educação e Habilidades da Organização para Cooperação e Desenvolvimento Econômico (EDU-OCDE) deu início a uma ambiciosa iniciativa internacional: o projeto OECD's Education 2030: The

\footnotetext{
3 Este estudo integra o ÁGUIA - Grupo de Estudos e Pesquisas sobre os Organismos Internacionais, Gestão e Políticas para a Educação Básica registrado do Diretório de Pesquisas do Conselho Nacional de Desenvolvimento Científico e Tecnológico - CNPq.
} 
Future of Education and Skills ${ }^{4}$. O empreendimento possui, como horizonte, o ano de 2030 e foi construído sob duas questões centrais: i) What knowledge, skills, attitudes and values will today's students need to thrive and shape their world? (ii) How can instructional systems develop these knowledge, skills, attitudes and values effectively?5 (OCDE, 2018b, p.1-2).

O projeto tem como objetivo desenvolver uma matriz conceitual de aprendizagem para o ano de 2030, com base em um cenário global de longo prazo, construído conjuntamente por stakeholders, experts, líderes de opinião, governos, empresários, gestores e entidades sociais. Doravante, utilizaremos o termo copartícipes para designar o conjunto de atores convidados pela OCDE a atuarem junto ao projeto. Dentre os denominados stakeholders, ou partes interessadas, a OCDE tem convidados atores que considera de interesse estratégico para o projeto, como agentes orgânicos de alto escalão dos governos nacionais. A matriz conceitual de aprendizagem resultante visa a apoiar os processos de reformas $e$ redesenhar currículos escolares nacionais "mais baseados em evidências e sistemáticos, por meio de uma análise curricular internacional" (OCDE, 2018b, p. 01). A OCDE justifica a empreitada da seguinte forma:

\begin{abstract}
as crianças que entram na escola em 2018 serão jovens adultos em 2030. As escolas estão enfrentando demandas crescentes para preparar os estudantes para rápidas mudanças econômicas, ambientais e sociais, para empregos que ainda não foram criados, para tecnologias que ainda não foram inventadas e para resolver os problemas sociais que ainda não foram antecipados. [...] A educação pode equipar os estudantes com a atuação, as competências e o senso de propósito para dar forma às suas próprias vidas e contribuir para aquelas dos outros. Portanto, a mudança é iminente (OCDE, 2018a, p._02, tradução e grifo nossos).
\end{abstract}

\footnotetext{
4 Educação 2030 da OCDE: O Futuro da Educação e das Habilidades. Doravante utilizaremos a expressão reduzida Projeto Educação 2030.

5 Em tradução nossa: (i) quais são os conhecimentos, habilidades, atitudes e valores que os estudantes que estão na educação básica em 2015 devem adquirir para prosperar e moldar o mundo em 2030? (ii) como os sistemas educacionais podem desenvolver esses conhecimentos, competências, habilidades, atitudes e valores de maneira efetiva?
} 
O Projeto Educação 2030 da OCDÉb está segmentado em duas fases. A primeira, com um cronograma de 2015 e 2018, volta-se para o quê, da substância à criação de uma matriz conceitual de aprendizagem para 2030, envolvendo, de forma cooperativa, os copartícipes para produzir e conduzir uma proposta de currículo internacional que possa mensurar e quantificar a aprendizagem dos estudantes por meio de testes comparativos.

A segunda fase, que conta apenas com data de partida (2019), debruça-se sobre o como, envolvendo a construção de descritores, princípios, conteúdos e desenhos didáticos que possam efetivamente implementar um currículo supranacional. Além disso, busca explorar os tipos de competências e perfis de professores que possam oferecer apoio a todos os estudantes "para alcançar os resultados desejados para o seu sucesso futuro" (OCDE, 2018b, p. 01).

A primeira fase (o quê) foi subdividida em duas partes: (a) elaboração de uma matriz conceitual de aprendizagem e (b) condução de uma proposta curricular internacional. Ambas as vertentes assentam-se na busca por consensos entre pares, o que, na prática, significa dizer que quem dispõe de mais poder de pressão, por meio de uma hegemonia discursiva, acaba por se impor, por conduzir as discussões. Neste sentido,

a chave para ganhar a hegemonia é geralmente daquele grupo que consegue estabelecer os parâmetros dos termos do debate, [...] que consegue incorporar as demandas de outros grupos que estão em competição no interior de seu próprio discurso sobre educação e metas sociais (BOWE; BALL, 1992, p. 26 apud SHIROMA; CAMPOS; GARCIA, 2005, p. 431-432).

Os demais países e instituições seguem, subscrevem e executam as concepções e decisões resultantes.

Na parte (a) da primeira fase (elaboração de uma matriz conceitual de aprendizagem), a OCDE visa a construir um consenso sobre os

\footnotetext{
6 O Projeto Educação 2030 da OCDE não deve ser confundido com a agenda Educação 2030 no âmbito dos dezessete objetivos de desenvolvimento sustentável coordenado pela UNESCO, mais especificamente o objetivo quatro (ODS-4): "Assegurar a educação inclusiva e equitativa e de qualidade, e promover oportunidades de aprendizagem ao longo da vida para todos". Mais informações sobre O ODS-4 podem ser encontradas em https://nacoesunidas.org/pos2015/ods4/.
} 
conhecimentos, habilidades, atitudes e valores percebidos como necessários para conformar as sociedades e as relações humanas em 2030. Trata-se de um movimento de convencimento dos copartícipes acerca de uma visão de sociedade e de educação em que se propõem objetivos para os sistemas educacionais dos países. É o momento, também, de definição de uma linguagem técnica entre os atores envolvidos, que facilite ou simplifique comparações de diferentes sistemas educacionais, com vistas a uma comunicação internacional mais fluida e à maior comparabilidade quanto às melhores práticas. A linguagem técnica, padronizada e os termos internacionais possibilitam, mais adiante, submeter os países a processos avaliativos comparativos padronizados de larga escala. Parece que são esforços que almejam certo isomorfismo de procedimentos em matéria educacional (diretrizes, ensino e aprendizagem) entre os países, no sentido não apenas de facilitar avaliações ou mensurações em escala global e ranqueamentos, mas de construir perfis desejáveis pelo âmbito produtivo. Em documento oficial, ressalta-se que

[...] a visão comum e a compreensão da "aprendizagem para 2030" baseiam-se em pesquisas que foram cuidadosamente revisadas, testadas e validadas por vários stakeholders, com vistas a uma relevância global, bem como a implicações políticas e práticas. A Matriz de Aprendizagem para 2030 dá base a um movimento global para acelerar a educação para um futuro melhor através de um processo interativo de co-criação e co-desenvolvimento envolvendo múltiplos stakeholders (OCDE, 2018b, p. 01, tradução nossa).

Partindo da ideia de um currículo supranacional, visa-se a um esforço global para alterar um currículo considerado estático e fragmentado na educação dos países, para um currículo dinâmico e interdisciplinar. Neste movimento, foi criado o Grupo Informal de Trabalho (IWG), para obter contribuições, perspectivas e experiências que auxiliem na construção de outro referencial de aprendizagem de alcance mundial, como segue.

QUADRO 01 - Instituições, atores e formas de contribuição no projeto

\begin{tabular}{|c|c|}
\hline Instituições e Atores & Formas de contribuição no projeto \\
\hline $\begin{array}{c}\text { Governos nacionais, } \\
\text { regionais e locais }\end{array}$ & $\begin{array}{l}\text { Compartilhar experiências sobre o desenho de suas políticas e } \\
\text { de seus currículos relacionados à diretriz curricular. }\end{array}$ \\
\hline
\end{tabular}

Revista Exitus, Santarém/PA, Vol. 9, N 5, P. 271 - 300, Edição Especial 2019. 
Estudantes, professores, dirigentes escolares e pais

Especialistas e pesquisadores

Setor empresarial e indústrias, associações profissionais e professores

Organizações e comunidades internacionais
Compartilhar práticas e experiências como exemplos concretos do uso da Bússola de Aprendizagem da OCDE.

Ajudar a fortalecer os vínculos entre política e prática baseados em evidências, especialmente nos constructos do referencial de aprendizagem.

Compartilhar práticas de apoio à aprendizagem e criar ambientes apropriados.

Contribuir com o diálogo no âmbito do projeto Educação 2030 da OCDE, em apoio ao Objetivo de Desenvolvimento Sustentável $4.7^{*}$ da ONU e a outras iniciativas relevantes.

Fonte: adaptado de OCDE (2018a).

* O objetivo 4.7 do ODS-4/ONU diz: "Educação para o desenvolvimento sustentável e para cidadania global" (UNESCO, [s.d.]). O Projeto Educação 2030 visa, também, a criar uma interface com o horizonte de 2030 dos ODS-4.

Já na parte (b) da primeira fase (análise curricular internacional), o Projeto Educação 2030 almeja empreender e construir uma proposta curricular internacional com conhecimentos, competências, atitudes e valores que permitam, aos países, implementar e modificar o desenho de seus currículos. Em termos operacionais, essa fase denominada aprendizagem internacional entre pares contou com evidências em outras experiências. Nesse diagnóstico, os copartícipes apuraram, conforme o quadro 02, a seguir, os fatores críticos e comuns nas políticas para educação dos países.

QUADRO 02 - Fatores críticos e comuns nas políticas de educação dos países

\begin{tabular}{|c|l|}
\hline $\begin{array}{c}\text { Fatores críticos } \\
\text { e comuns }\end{array}$ & \multicolumn{1}{c|}{ Descrição } \\
\hline $\begin{array}{c}\text { Sobrecarga } \\
\text { curricular }\end{array}$ & $\begin{array}{l}\text { Os governos são confrontados com as necessidades e solicitações de } \\
\text { pais, universidades e empresários. As escolas têm enfrentado sobrecarga } \\
\text { tempo suficiente para dominar os principais conceitos disciplinares ou } \\
\text { nutrir amizades, usufruir do sono e de exercícios físicos. Há, portanto, uma } \\
\text { percepção de que se deve mudar o foco de mais horas para aprender } \\
\text { para tempo de aprendizado de qualidade. }\end{array}$ \\
\hline $\begin{array}{c}\text { Defasagem } \\
\text { temporal }\end{array}$ & $\begin{array}{l}\text { As reformas curriculares sofrem de atrasos entre o reconhecimento de } \\
\text { sua necessidade, a tomada de decisão, a implementação e os seus } \\
\text { efeitos práticos. A diferença entre a intenção do currículo e o resultado } \\
\text { da aprendizagem é, geralmente, muito ampla. }\end{array}$ \\
\hline Qualidade & $\begin{array}{l}\text { Distância entre os conteúdos e as necessidades do mercado. O } \\
\text { conteúdo deve ser de alta qualidade para que os estudantes } \\
\text { aprendam e adquiram uma compreensão mais profunda. }\end{array}$ \\
\hline Equidade & $\begin{array}{l}\text { Os currículos devem garantir a equidade ao mesmo tempo em que } \\
\text { inovam; exige-se que todos os estudantes possam se beneficiar das } \\
\text { mudanças sociais, econômicas e tecnológicas. }\end{array}$ \\
\hline
\end{tabular}

Revista Exitus, Santarém/PA, Vol. 9, № 5, p. 271 - 300, Edição Especial 2019. 
Implementação O planejamento e o alinhamento cuidadosos são extremamente efetiva importantes para a implementação efetiva das reformas nos países.

Fonte: Adaptado de OCDE (2018b, p. 02, tradução nossa).

A partir deste diagnóstico comum, o Projeto Educação 2030 almeja construir um plano curricular internacional que defina princípios, descritores, competências e conteúdos curriculares, que possam ser adotados como base pelos governos nacionais, com elementos comparativos para mensurar o desempenho dos estudantes e que possa perdurar em diferentes países ao longo do tempo.

Para tanto, foram definidos quatro eixos investigativos: (i) "Policy Questionnaire on Curriculum Redesign (PQC)"; (ii) "Curriculum Content Mapping (CCM)"; (iii) "Stock-taking Exercise on Physical \& Health Education"; (iv) "Mathematics Curriculum Document Analysis Project (MCDA)" (OCDE, 2018b, p. 02)7. Estes eixos mapeiam tendências, avaliam capacidade de execução dos países, captam dados e falhas que subsidiarão a construção do currículo internacional, conforme segue.

QUADRO 03 - Eixos de trabalho para construção do currículo supranacional

\begin{tabular}{|c|c|}
\hline $\begin{array}{l}\text { Questionário de } \\
\text { Políticas Públicas } \\
\text { sobre Redesenho } \\
\text { Curricular (PQC) }\end{array}$ & $\begin{array}{l}\text { O exercício PQC oferece, aos países, a oportunidade de aprender } \\
\text { com seus pares sobre boas práticas e desafios no redesenho } \\
\text { curricular, sobre iniciativas e estratégias em políticas educacionais. O } \\
\text { PQC também mapeia tendências dentre os vários contextos dos } \\
\text { países. }\end{array}$ \\
\hline $\begin{array}{l}\text { Mapeamento de } \\
\text { Conteúdo } \\
\text { Curricular (CCM) }\end{array}$ & $\begin{array}{l}\text { O exercício CCM visa a identificar em que medida as competências } \\
\text { que refletem demandas emergentes (por exemplo, competências } \\
\text { globais, alfabetização digital, colaboração, pensamento crítico, } \\
\text { criatividade e empatia) estão presentes no currículo existente dos } \\
\text { países. Isto permite aos governos identificar a área de aprendizagem } \\
\text { (por exemplo, matemática, ciências naturais, artes etc.) em que uma } \\
\text { determinada competência (por ex. criatividade) aparece mais } \\
\text { proeminentemente em currículos escritos. Os resultados fornecerão } \\
\text { importante benchmarking e dados comparativos que podem ajudar } \\
\text { no desenvolvimento curricular futuro. }\end{array}$ \\
\hline
\end{tabular}

7 Em tradução nossa: (i) Políticas Públicas sobre o Redesenho Curricular, (ii) Mapeamento de Conteúdo Curricular, (iii) Exercício de levantamento sobre Educação Física e Educação em | Saúde, -e (iv) Projeto de Análise Documental sobre Currículo de Matemática. 


\begin{tabular}{|c|c|}
\hline $\begin{array}{l}\text { Exercício de } \\
\text { levantamento } \\
\text { sobre Educação } \\
\text { Física e Educação } \\
\text { em Saúde }\end{array}$ & $\begin{array}{l}\text { É a primeira vez que a OCDE se concentra na Educação Física e na } \\
\text { saúde como parte de sua análise de políticas. Esse exercício faz um } \\
\text { balanço de evidências de pesquisas sobre os efeitos da Educação } \\
\text { Física/educação em saúde. Também procura descobrir novos } \\
\text { conhecimentos sobre o estado das políticas de Educação } \\
\text { Física/Educação em saúde sobre currículo, práticas e perspectivas } \\
\text { em vários países. }\end{array}$ \\
\hline $\begin{array}{l}\text { Projeto de Análise } \\
\text { Documental sobre } \\
\text { Currículo de } \\
\text { Matemática } \\
\text { (MCDA) }\end{array}$ & $\begin{array}{l}\text { O projeto MCDA investiga até que ponto os países têm incorporado } \\
\text { perspectivas amplas de letramento matemático e das habilidades do } \\
\text { século } 21 \text { no currículo de Matemática, por meio de um Referencial de } \\
\text { Matemática para o Século XXI, desenvolvido para este projeto em } \\
\text { conjunto com o estudo PISA 2021. }\end{array}$ \\
\hline
\end{tabular}

Fonte: OCDE (2018b, p. 02, tradução nossa).

A segunda fase do Projeto Educação 2030 (o como) visa a construir uma proposta curricular comum, com princípios, descritores, competências, conteúdos e desenhos didáticos que possam levar à efetiva implementação nos currículos nacionais. Nesta fase do projeto, objetiva-se criar ferramentas curriculares interativas, pesquisas sobre políticas públicas curriculares, mapeamentos de conteúdo curricular e análise de currículo sobre Matemática (em específico), de modo a tornar o projeto o mais científico possível, e de modo a fazê-lo refletir as demandas das sociedades modernas. Para a OCDE, este trabalho ajudará os países a enfrentarem os desafios comuns de implementação curricular e identificar fatores críticos de sucesso. Ainda segundo a Organização, a revisão de mecanismos de implementação curricular garante o sucesso de todos os estudantes e pode ajudar os países a elevar a qualidade e a equidade na aprendizagem, o que, por sua vez, pode levar a melhores resultados sociais e econômicos para os indivíduos e a sociedade em geral (OCDE, 2018b).

A ambição do projeto demonstra como se tem intensificado as formas de atuação da $O C D E$, seja por sua capacidade orgânica de conduzir e liderar projetos econômicos internacionais, seja pela persuasão ideológica como portadora de um único caminho para a Educação Básica, ou, ainda, pela estreita visão de que o currículo prescrito em si pode promover mudanças. Trata-se de um pragmatismo de gênese econômica aplicado ao terreno educacional. De um modo ou de outro, acaba por sedimentar visões que corroboram um projeto econômico hegemônico pela educação. 
Cada vez mais se têm intensificado a parceria e a anvência dos governos nacionais frente às decisões e proposições dos comitês intergovernamentais da OCDE. Se até o início deste século predominavam as pautas voltadas ao comércio, tributação, investimentos, finanças, serviços, energia, siderurgia e economia do trabalho, as relações cooperativas atuais incluíram a educação no centro dos debates e acoplaram-na às searas econômico-comercias. Crescentemente, a Educação Básica tem-se tornado objeto de disputa comercial dos homens do capital. Exige-se, deste modo, tornar visíveis e apurar tais conexões, além das implicações na Educação Básica e, neste sentido, avançamos para apreender a essência e os elementos invisíveis deste projeto.

\section{A BÚSSOLA DE APRENDIZAGEM DA OCDE: CORAÇÃO DO PROJETO EDUCAÇÃO 2030}

Nos documentos disponíveis do projeto (OCDE, 2018a, 2018b), a OCDE detalhou os pressupostos-base às rápidas e profundas mudanças e impactos econômicos (conhecimento científico e interdependência financeira), ambientais (mudança climática e esgotamento de recursos naturais) e sociais (mudanças demográficas, desigualdades e instabilidades), aproximando-se do escopo político dos Objetivos Globais da ONU para o Desenvolvimento Sustentável (ODS) de 2030, "com o objetivo de garantir a sustentabilidade das pessoas, do lucro, do planeta e da paz através de parcerias" (OCDE, 2018a, p. 3, tradução nossa).

Neste cenário internacional de crises cíclicas do capitalismo, empresários, líderes mundiais, multimilionários e governos recompõem os interesses que fazem girar a economia e a política. Neste movimento de recomposição de poder, a OCDE sobressai-se como força política capaz de frear fatores críticos da economia e capitaliza a educação, ora como nicho para negócios rentáveis, ora (com face visível) ao preconizá-la como caminho para a inclusão, a sustentabilidade e o bem-estar. Para tanto, conforma a definição dos objetivos para o aluno e para a educação: 
aprender a formar objetivos claros e propositais, trabalhar com outras pessoas com diferentes perspectivas, encontrar oportunidades inexploradas e identificar várias soluções para grandes problemas será essencial nos próximos anos. A educação precisa ter como objetivo fazer mais do que preparar os jovens para o mundo do trabalho; ela precisa equipar os estudantes com as habilidades necessárias para se tornarem cidadãos ativos, responsáveis e engajados (OCDE, 2018a, p. 04, tradução nossa).

Neste mesmo sentido, a OCDE prossegue com uma crença salvífica ao afirmar que, em sua vida acadêmica, o indivíduo deve possuir um sentido de atuação, uma proatividade ou um protagonismo (do inglês agency):

a ałuação implica uma sensação de responsabilidade de participar do mundo e, ao fazê-lo, de influenciar pessoas, eventos e circunstâncias para melhor. A atuação exige a capacidade de definir um propósito orientador e identificar ações para atingir um objetivo (OCDE, 2018a, p. 04, tradução nossa).

Para este propósito, afirma que a atuação do estudante poderia ser desenvolvida na escola pelo professor, mediante uma prática colaborativa de co-atuação (co-agency), que expande a atividade relacional do estudante para além da sala de aula, envolvendo sua família e sua comunidade. Segundo a OCDE, dois fatores são preponderantes ao protagonismo do estudante:

- primeiro é um ambiente de aprendizagem personalizado, que apoie e motive cada estudante a nutrir suas paixões, a fazer conexões entre diferentes experiências e oportunidades de aprendizagem, e a projetar seus próprios projetos e processos de aprendizagem em colaboração com os outros. O segundo é a construção de uma base sólida: a alfabetização e a numeracia continuam sendo cruciais. Na era da transformação digital e com o advento do big data, a alfabetização digital e a alfabetização de dados estão se tornando cada vez mais essenciais, assim como a saúde física e o bem-estar mental (OCDE, 2018a, p._4, tradução e grifo nossos).

Do exposto, extrai-se a relevância de um ambiente de aprendizagem personalizado, aliado ao letramento, percepção numérica e de códigos matemáticos, letramento digital, saúde física e bem-estar mental. Ao priorizar um tipo de formação para o estudante, o projeto The Future of Education and Skills - Education 2030 cria outro referencial de aprendizagem, simbolicamente denominado bússola de aprendizagem, em que o indivíduo necessita de um direcionamento quanto às competências a serem 
desenvolvidas para se inserir ou navegar na sociedade. A bússola de aprendizagem oferece uma direção e finalidades da e para a educação.

FIGURA 01 - Bússola de Aprendizagem da OCDE para 2030

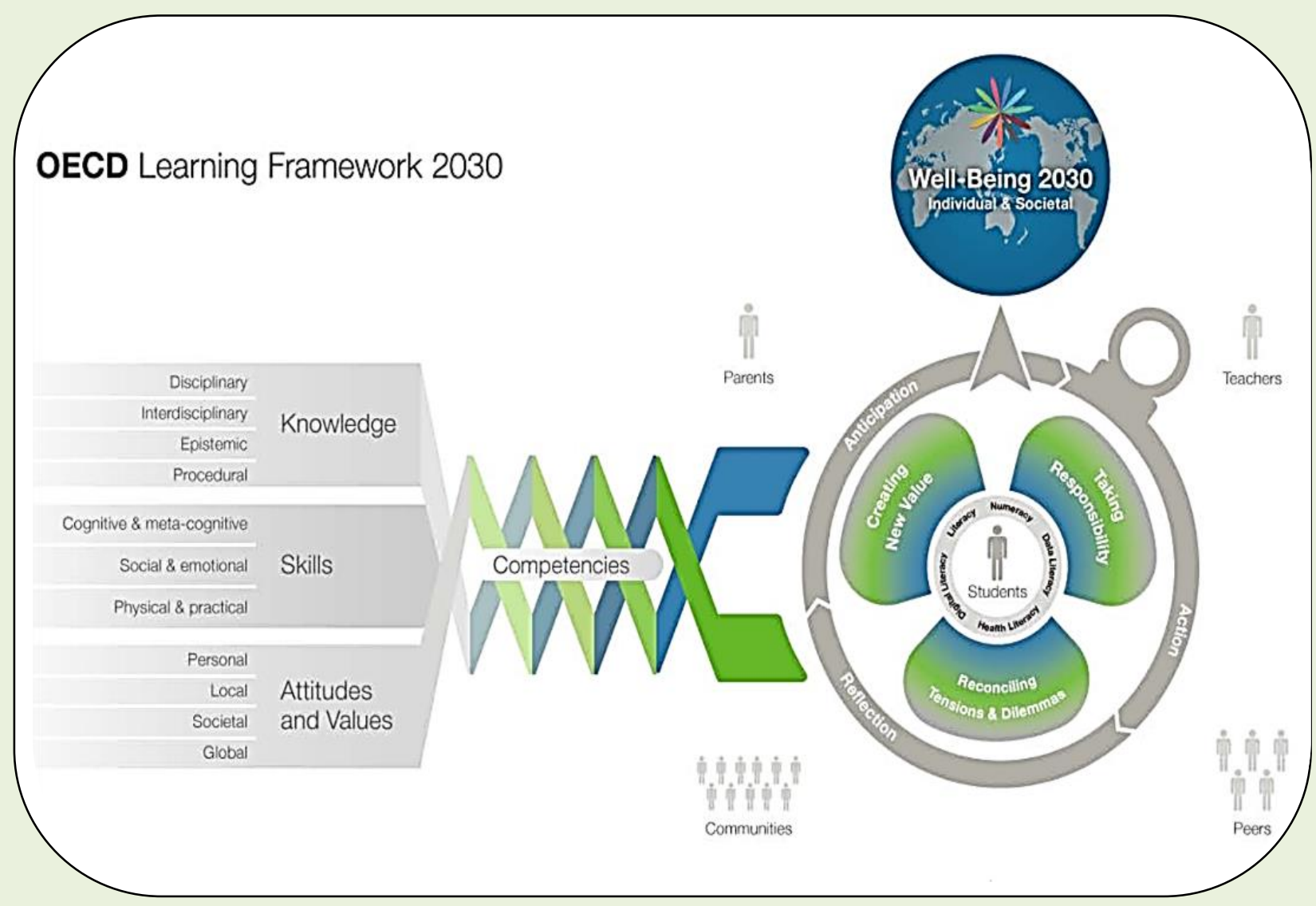

No centro da bússola de aprendizagem está o estudante, diante de três ações: criar novos valores, assumir responsabilidades e reconciliar tensões e dilemas (OCDE, 2018a). Essas ações são encerradas em três capacidades consideradas fundamentais: antecipação, reflexão e atuação. Na figura à esquerda, alimentando a bússola proposta, estão dispostas as competências (knowlegde, skills, attitudes and values) com seus conteúdos a atuar de forma intricada.

Se examinarmos a imagem disposta acima e as publicações da OCDE, constata-se um foco no indivíduo, indo ao encontro da ideia de atuação ou agency (em inglês), entendida como o grau ou capacidade de indivíduos, jovens e comunidades de serem proativos, inovadores, atentos, responsáveis, detentores de um senso de certo e errado, sensibilidade às reivindicações 
dos outros indivíduos e boas noções quanto aos limites das ações individuais e coletivas.

Adicionalmente, a bússola traz a ideia de coatuação (aprendizagem como atributo coletivo), que não ocorre de forma isolada, senão por meio do reconhecimento dos professores de como as pessoas aprendem de formas distintas, requerendo apoio conforme as necessidades individuais, construindo relacionamentos fortes entre professores ou pares, com os pais e com as comunidades. Supõem-se, aqui, relações interativas, de auxílio mútuo, que orientam os estudantes no desenvolvimento da capacidade de atuação. Também de professores que reconhecem a individualidade dos estudantes e saibam estabelecer relações com outros professores ou pares, famílias e comunidades. A bússola é instrumento de precisão, indica os pontos cardeais e serve de guia aos navegantes. A respeito, afirma a OCDE:

[...] como um mapa, não diz onde você deve ir, mas quais são as possibilidades; pode permitir pensamentos divergentes, mostrar outros lugares, outras formas de pensar. Esta é a ideia principal do novo referencial: alargar nossa forma de pensar e criar uma linguagem comum, que possibilite o diálogo (OCDE, 2018a, p. 04, tradução nossa).

Neste caso, a bússola pode indicar aos governos, secretários de educação, empresários e outros stakeholders uma concepção e as finalidades da educação, enfim, um direcionamento. Esta visão dominante, analisada por Shiroma, Campos e Garcia (2005), Freitas (2011a, 2011b, 2012) e Pereira (2016) evidencia o predomínio das relações de poder político e dominação intelectual, além de atualizar argutas maneiras de recolonizar, sob a aparência de ajuda ou cooperação.

Merece destaque o conceito de aprendizagem como um atributo coletivo. Neste sentido, pode-se pensar que os conteúdos e as maneiras de aprender são daqueles que fazem a educação, resguardando as culturas, as identidades, com e para aquele que ensina e aquele que aprende, em uma relação mútua (FREIRE, 2002). Não é este o pressuposto contido aqui, na aprendizagem como um atributo coletivo, pois, na essência, o que se quer afirmar é um modelo de aprendizagem para alguns, para poucos. 
Apresenta-se como universal aquilo que é particular. São os interesses e a sociabilidade neoliberais que se apresentam com universais (IASI, 2019).

Outro destaque do documento da OCDE (2018a) diz respeito à ênfase colocada sobre o indivíduo como um ser isolado, abstrato e individual. Sobre ele recai toda a responsabilidade para resolver os problemas econômicos, sociais e ambientais. Nada foi dito sobre as ações deletérias e as responsabilidades das empresas transnacionais; também nada foi dito sobre concentração de riquezas. Nada foi escrito sobre as estruturas que geram as desigualdades econômicas e sociais. No fundo, a suposta liberdade formal de escolha encobre profundas desigualdades sociais e regionais. Tem-se, assim, um projeto que se debruça sobre bases epistemológicas e metodológicas de superfície na área educacional, mas que ocultam uma base socioeconômica, com uma ontologia humana inerente, sobre a qual não se dialoga.

Pois bem, ainda sobre a bússola de aprendizagem, tem-se, assim, um conjunto de competências e habilidades que subsidiam um padrão cíclico comportamental de antecipação, ação e reflexão para que o indivíduo atue sobre seu meio conforme os seguintes padrões de conduta que 0 levarão ao bem-estar futuro:

1. Criar novos valores: processo de criar, fazer, trazer à tona e formular resultados inovadores, originais, contribuindo com algo de valor positivo intrínseco. Trata-se da capacidade que mais distingue o ser humano da inteligência artificial. Compõe constructos, como criatividade, pensamento criativo e inventivo, curiosidade, pensamento global.

2. Conciliar tensões e dilemas: capacidade de harmonizar interesses e perspectivas distintas em um mundo visto como estruturalmente em desequilíbrio e complexo. Compõe constructos como empatia, resiliência, resistência a estresse e confiança.

3. Assumir responsabilidades: definido como achar seu lugar no mundo. Em outras palavras, lidar com novidades, mudanças, diversidades e ambiguidade pressupõe que os indivíduos possam pensar por eles 
mesmos, o que sugere senso de responsabilidade, maturidade. Capacidade do indivíduo de refletir e avaliar suas ações, experiências e objetivos pessoais, habilidade de aprender a aprender e de resolver problemas.

Ao examinar as prescrições, pode-se constatar como a Educação Básica vem sendo tomada como nicho estratégico de exploração econômica, entrelaçada com múltiplos avanços tecnológicos. Ainda, ao mesmo tempo, atribuindo ao estudante a responsabilidade para aprender a viver junto, adaptar-se às preconizações futuras das relações de trabalho e a ser consumidor de novos produtos e dos serviços. Segundo Andreas Schleicher, Diretor de Educação da OCDE, em apresentação oficial pública da organização sobre o projeto, as revoluções intestinas do sistema capitalista de produção, ao longo dos séculos, geraram movimentos pendulares entre desenvolvimento tecnológico e desenvolvimento educacional das sociedades. No momento atual (2018) ocorre uma revolução digital que supera a capacidade de compreensão das pessoas:

\begin{abstract}
trata-se de uma Revolução digital e novamente a tecnologia à frente da capacidade das pessoas e a emergência de sofrimento social. A questão por trás do projeto educação 2030 é como mover as capacidades humanas novamente à frente da tecnologia, de modo que esta se transforme em uma ferramenta de empoderamento para nós. Quer dizer, é uma luta entre humanos e tecnologias e não entre classes sociais (SCHLEICHER, 20188).
\end{abstract}

O trecho da apresentação selecionado traz elementos da essência do Projeto Educação 2030. De forma objetiva, atualiza uma visão de mundo, de sociedade e de educação, que tem seus pressupostos erguidos no individualismo, na competição, no livre mercado e na flexibilidade, típicos dos neoliberais. Supõem que o indivíduo, por si, faça melhorias na vida coletiva. Atribui a ele o fracasso ou sucesso na vida; exige dele competir e adaptar-se às circunstâncias adversas. Prossegue em visões e ações para o capital, a ponto de afirmar que o que existe "[...] é uma luta entre humanos

\footnotetext{
8 As referências a este autor são de apresentação em vídeo e, por esta razão, não há número de página, mesmo se tratando de citação direta.
} 
e tecnologias e não entre classes sociais", evidenciando a essência do projeto. E conclui: "o mundo está dividido entre os humanos e as tecnologias" (SCHLEICHER, 2018). De fato, o mundo está divido entre aqueles que possuem e tem acesso às tecnologias e aqueles que não possuem nem acesso e nem tecnologias. Estes sim, duplamente excluídos, estão à margem e vigiados pelo sistema!

Este argumento, de tomar o particular como universal, tornou-se o modus operandi de persuasão da OCDE, pois encobre o real, as estruturas econômicas, as desigualdades sociais e o empobrecimento de muitos. Ao atuar de forma orgânica, camufla a luta de classes sociais, a divisão social do trabalho, as diferentes culturas, o desemprego estrutural, mas supõe que o avanço tecnológico beneficia igualmente a todos. Neste movimento histórico de reprodução capitalista, os avanços tecnológicos dos meios de produção, circulação e consumo afetam, sim, a vida dos trabalhadores. Pode parecer que as ideias rompem fronteiras. Contudo, o modo de produção da vida material produz as relações políticas, jurídicas de exploração, dominação e subordinação, agora sob o véu de luta entre humanos e tecnologias.

O Projeto Educação 2030 da OCDE apoia-se em outro projeto da década de 1990, conduzido e liderado pelo Escritório Federal de Estatísticas da Suíça (SFSO) e denominado Definition and Selection of Competencies: Theoretical and Conceptual Foundations ${ }^{9}$ - DeSeCo. O projeto DeSeCo serviu de base para a estruturação das matrizes referenciais de avaliação do Programa Internacional para Avaliação de Estudantes (PISA), que despontava nos anos 2000. Indagava:

[...] além das habilidades básicas como ler, escrever e calcular, quais competências são necessárias para o indivíduo levar uma vida global bem-sucedida e responsável, e para a sociedade contemporânea enfrentar desafios presentes e futuros? Quais são os fundamentos normativos, teóricos e conceituais para definir e selecionar um conjunto limitado de competências mais relevantes? (OCDE, 2001, p. 02, tradução nossa).

\footnotetext{
9 Em português - Definição e Seleção de Competências: Fundamentos Teóricos e Conceituais.
} 
Dentre os projetos germinais da OCDE na busca por matrizes conceituais que estandardizam competências-chave necessárias a que os jovens alcancem uma vida de sucesso e uma sociedade que funciona bem está a iniciativa DeSeCo. O projeto trouxe o conceito de competência como a mobilização de recursos psicossociais, como habilidades de atitudes para a solução de problemas do dia a dia. Em pouco tempo, os países passaram a adotar esse vocabulário em discursos, legislação e ações.

No entanto, no Projeto Educação 2030 (2018a, 2018b), a OCDE ampliou o conceito de competência advindo dos programas internacionais anteriores: PISA, TALIS e PIAAC. Ele passou a integrar conhecimento, habilidades, atitudes e valores que serão desenvolvidos na sala de aula. Ainda que atitudes e valores possam ser adquiridos pelo estudante, 0 documento preconiza que,

ao passo a vida humana é enriquecida pela diversidade de valores e atitudes decorrentes de diferentes perspectivas culturais e traços de personalidade, existem alguns valores humanos [...] que não podem ser comprometidos (OCDE, 2018a, p. 6, tradução nossa).

Portanto, há uma contradição endógena no projeto coordenado pela OCDE, ao propor um currículo e uma educação que formem cidadãos ativos, responsáveis, engajados e plenos e, ao mesmo tempo, indicar uma sociabilidade inexorável, definitiva e imutável. Escamoteiam-se as possibilidades de mudanças. Ofuscam-se alternativas de ser cidadão pleno, de ser um sujeito histórico, ativo, propositivo, capaz de enxergar as determinações históricas que o mantém subjugado às vicissitudes do capital e de ser capaz de modificá-las. Neste sentido, nos lembra Libâneo (2012) que, nesta sociabilidade capitalista, o que há é uma educação de acomodação, de subordinação aos desígnios de acumulação e reprodução do capital.

As competências transformativas, nome atribuído pela OCDE ao conjunto de conhecimentos, habilidades, atitudes e valores tidos como indispensáveis para 2030, formam um conjunto de constructos específicos, 
passíveis de inclusão nas propostas curriculares nacionais para promover criatividade, pensamento crítico, responsabilidade, resiliência, colaboração.

Formado este paradigma epistemológico, com a marca de uma bússola para o bem-estar do estudante no futuro, o Projeto Educação 2030 detalha os descritores e as perspectivas a serem observadas pelo governo nos currículos nacionais. A crença assumida é a passagem de um currículo predeterminado e estático para a um modelo adaptável e dinâmico. Nesta linha, são delineados os princípios curriculares basilares a serem seguidos, conforme o quadro a seguir.

QUADRO 04 - Educação 2030: princípios basilares para currículo nacional

\begin{tabular}{|c|c|c|}
\hline Foco e rigor & $\begin{array}{c}\text { Número reduzido de tópicos a ser introduzido em cada ano escolar para } \\
\text { garantir a profundidade e qualidade da aprendizagem. A sobreposição } \\
\text { de conceitos-chave é vista como positiva. Tópicos desafiadores e } \\
\text { condutíveis para pensamento e reflexão profundos. }\end{array}$ \\
\hline Coerência & $\begin{array}{r}\text { Tópicos devem ser sequenciados do básico ao avançado para dar lógica } \\
\text { à disciplina acadêmica. }\end{array}$ \\
\hline Alinhamento & $\begin{array}{c}\text { O currículo deve estar alinhado com as práticas de ensino e a avaliação. } \\
\text { Busca por novos métodos de avaliação voltados a resultados e a aços. }\end{array}$ \\
\hline Transferibilidade & $\begin{array}{r}\text { Prioridade a conhecimentos, habilidades, atitudes e valores passíveis de } \\
\text { utilizaça em diferentes contextos. }\end{array}$ \\
\hline professor do & $\begin{array}{r}\text { Empoderado para utilizar seus conhecimentos profissionais, habilidades e } \\
\text { experiência para efetivamente trazer o currículo à sala de aula. }\end{array}$ \\
\hline Autenticidade & $\begin{array}{r}\text { Vinculação das experiências de aprendizado do estudante ao mundo } \\
\text { real e aprendizagem pautada por senso de propósito. }\end{array}$ \\
\hline Inter-relação & $\begin{array}{c}\text { Oportunidade de o estudante descobrir como um tópico ou conceito } \\
\text { pode se vincular e se conectar a outros tópicos ou conceitos dentro e } \\
\text { entre disciplinas e com a vida real fora da escola. }\end{array}$ \\
\hline Flexibilidade & $\begin{array}{c}\text { Currículo flexível, de "predeterminado e estático" para "adaptável e } \\
\text { dinâmico". Escolas e professores capazes de atualizar e alinhar o currículo } \\
\text { para refletir demandas sociais em evolução e necessidades individuais de } \\
\text { aprendizagem. }\end{array}$ \\
\hline
\end{tabular}

Fonte: adaptado de OCDE (2018a, p. 6-7; 2018b, tradução nossa).

\section{CONEXÕES ENTRE AS PROPOSIÇÕES EXTERNAS E AS POLÍTICAS CURRICULARES NACIONAIS}

Em 2002, no âmbito da OCDE, criou-se a Diretoria de Educação e Habilidades, com capacidade para traduzir, na esfera educacional, um modelo econômico e tecnológico supranacional. Para tanto, a estratégia política assumida foi a de tomar educação como um objeto traduzível em perspectiva econômica, comercializável, um nicho de negócios econômicos 
e tecnológicos rentáveis. Deve-se notar que, historicamente, a organização internacional, que foi criada sobre a perspectiva da política internacional pelo lado econômico, trata a educação na perspectiva de crescimento econômico, em função da expansão de capital humano. Em outras palavras, a educação é um investimento e, como tal, seu planejamento é afeto aos economistas da educação. Contudo, enquanto vocabulário discursivo ao longo do tempo, a ideia é a de que a educação e, em especial, o currículo devem ser submetidos "às demandas da sociedade moderna". Entretanto, já na criação do Centro para Pesquisa e Inovação Educacional (CERI) da OCDE, em 1968, essa premissa estava presente.

Deste modo, nos momentos de crise do capital, empresários e empresas transnacionais veem na educação um nicho a potencializar negócios econômicos e tecnológicos e buscam ampliar mercados consumidores de produtos e oferta de serviços. De maneira visível, essa organização passou a produzir e conduzir a política de melhores práticas como instrumento procedimental e estratégico para potencializar ideologias. Empresas transnacionais e grupos de corporações demandam uma concepção de educação que, assumida pelos diretores, stakeholders e experts orgânicos da OCDE atuam junto aos governos para abertura de negócios na Educação Básica pública como um serviço público sujeito e conduzido pelas regras de livre mercado ${ }^{10}$.

Assim, busca-se incidir na política curricular, pois esta trás os pressupostos pedagógico-ontológicos, em outras palavras, que ser humano se quer formar, para quê formar, para que tipo de sociedade? No entanto, sabemos que o fazer pedagógico não se separa do fazer político; antes, estão imbricados (FREIRE, 2002). E neste movimento supranacional gradual, emergem-se contradições ao se propor políticas curriculares baseadas em flexibilidade e autonomia, mas que, pari passu, semeiam o horizonte para as competências que são muito mais úteis às preconizações da reestruturação produtiva. A bússola de aprendizagem adotada para o projeto Educação

10 Sobre corporações, fundações e avanço das ações de privatização da educação pública, ver Adrião (2018), Freitas (2012) e Adrião e Domiciano (2018). 
2030, coordenado pela OCDE, reposiciona tanto o conhecimento, as habilidades, as atitudes e os valores quanto às competências transformativas dos estudantes. O empreendimento busca uma formação escolar internacional padronizada, com desenhos curriculares que traçam proposições tanto para a sala de aula quanto para a relação professoraluno. E nesse sinuoso e contraditório roteiro, afirma como preparar o indivíduo para o exercício pleno da cidadania burguesa neoliberal (full citizenship). Contudo, cabe aqui recorrer à advertência de lasi:

Os liberais apontavam para a ideia de que o capitalismo plenamente desenvolvido iria, paulatinamente, resolvendo os problemas da humanidade, as desigualdades sociais, as desigualdades de riquezas, as desigualdades regionais, o acesso à cultura, a expansão dos serviços, o acesso a bens e serviços essenciais a todos; aquilo que Marshall chegou um dia a chamar de "Plena Cidadania". Ora, o capitalismo real é o inverso disso, quanto mais ele cresce, ele vai reduzindo o acesso a bens, serviços e direitos para a grande parte da população (2019, p. 25).

Mas por que um currículo supranacional? Como nos lembram Shiroma, Campos e Garcia (2005) e Faria Filho (1998), não podemos subestimar a capacidade dos homens do capital e das elites nacionais, mas é necessário revelar, com rigor científico, os elementos invisíveis desse projeto e provocar as ações e reflexões que recompõem a educação como direito social e subjetivo. Sabem os experts da OCDE que as culturas dos países são muito distintas. Então, que razões para desenvolver um projeto curricular supranacional? Trata-se de um movimento de hegemonia discursiva, em que instituições de alcance internacional têm desenvolvido discursos, ações, projetos e slogans específicos, utilizando termos como bem-estar, inclusão, flexibilidade, autonomia, currículo, competências e outros para, de forma supranacional, tornar os gabinetes das cúpulas dos governos e secretarias de educação copartícipes de seu projeto.

A vulgarização do "vocabulário da reforma" pode ser considerada uma estratégia de legitimação eficaz na medida em que consegue "colonizar" o discurso, o pensamento educacional e se espalhar no cotidiano como demanda imprescindível da "modernidade" (SHIROMA; CAMPOS; GARCIA, 2005, p. 429). 
Entretanto, por mais que a hegemonia discursiva propagasse a ideia de necessidade de novas competências para além de matemática, leitura e ciências, os domínios inovadores propostos sempre se curvam à ideia de capacitar o indivíduo para que se adapte às mudanças socioeconômicas do avanço de uma sociabilidade adstrita ao sistema capitalista de produção. Em relatórios, publicações diversas, reuniões de cúpula, reuniões técnicas e demais foros de compartilhamento de ideias e conhecimentos não se questiona como o estudante pode ser formado para além de se adaptar e sobreviver a mudanças conjunturais. Buscam-se determinar competências, habilidades, atitudes e comportamentos a serem adquiridos para que, ao término de sua formação compulsória, o indivíduo esteja apto a recompor as bases infraestruturais do modo de produção vigente. Em outras palavras, mudar sem transformar a acumulação de riquezas!

\begin{abstract}
Globalização e modernização estão criando um mundo cada vez mais diversificado e interconectado. Para fazer sentido e funcionar bem nesse mundo, os indivíduos precisam, por exemplo, dominar a mudança de tecnologias e encontrar sentido na quantidade de informação disponível. Eles também enfrentam desafios coletivos enquanto sociedades, como equilibrar crescimento econômico com sustentabilidade ambiental, e prosperidade com equidade social. Nestes contextos, as competências que os indivíduos precisam para atingir seus objetivos tornaram-se mais complexas, exigindo mais do que domínio de certas habilidades estreitamente definidas (OCDE, 2005, p. 04, tradução nossa).
\end{abstract}

Para Schleicher (2018), O projeto Educação 2030 busca "entendimentos comuns", fornece aos países "uma forma de olhar para fora; como um mapa: não diz onde você deve ir, mas quais são as possibilidades" Contudo, ao definir quais são as possibilidades, acaba-se por exercer pressões políticas e por sedimentar visões hegemônicas. Prossegue Schleicher (2018), afirmando que se busca definir

uma linguagem compartilhada que possa facilitar a comparação entre uma ampla variedade de sistemas educacionais por meio da qual cada parte interessada possa se comunicar de forma eficaz, aprender e comparar as melhores práticas.

Como atua a OCDE nos países membros? Para serem incluídos no circuito de poder global, ou no clube dos ricos, os governos participam e 
subscrevem convenções, acordos, tratados, programas e projetos junto à organização. Neste caso, estabelecem sinergias políticas por meio de revisão por pares, divulgação de indicadores comparativos, relatórios, publicações de documentos, disseminação de vocabulários protocolares e de "tendências" da educação para, em seguida, revesti-las de significado consoante "as melhores políticas públicas para vidas melhores, crescimento inclusivo e ambiente de aprendizagem inovador" (OCDE, 2011 , p. 09, 10). No caso do Brasil, o site oficial do Ministério das Relações Exteriores, relativo à relação Brasil-OCDE, cita que "diversos países em desenvolvimento têm buscado aderir à OCDE, pois, o ingresso na organização equivaleria à obtenção de um 'selo de qualidade', que poderia estimular investimentos e a consolidação de reformas econômicas".

A página eletrônica do projeto Educação 2030 informa que

a visão comum e a compreensão do aprendizado para 2030 baseiam-se em pesquisas que foram cuidadosamente realizadas, testadas e validadas por várias partes interessadas quanto à relevância global, bem como às implicações políticas e práticas (OCDE, 2018b, p. 01, tradução nossa).

Entretanto essas pesquisas proveem, em sua quase totalidade, de instituições ou especialistas das nações centrais, o que acaba por reforçar discursos hegemônicos em educação. As contribuições de (especialistas de) países periféricos, que carregam realidades muito distintas, servem, assim, apenas para dar um ar de legitimidade internacional às discussões encetadas. Ainda, o olhar do centro para a periferia traz sempre consigo suas próprias concepções ontológicas, epistêmicas e metodológicas a serem transplantadas como modelos de sucesso na área de educação.

Assim, utiliza-se de pesquisas e experiências de países considerados referências na esfera educacional e as tomam como parâmetros de melhores práticas a serem replicadas em nações menos desenvolvidas. Os modelos tidos como exitosos são aqueles que comportam os mais avançados modelos de desenvolvimento do sistema capitalista de produção e alto desenvolvimento tecnológico frente à divisão internacional de trabalho. Deste modo, exportam-se políticas consonantes ao sistema 
econômico internacional, que exigem adequações nacionais, passando pela Educação Básica, de modo a garantir continuidade, em escala global, à lógica do capital e da sociabilidade burguesa que o objetiva.

Este movimento, que é histórico-dialético, deixa-se transparecer por alguns elementos que caracterizam atuação da organização. Pode-se constatar uma relação de hierarquia nas instâncias deliberativas da OCDE, pois o controle político aparece quase pronto nas reuniões decisórias, revestindo-se de consenso. Por vezes, a OCDE convida países, instituições e especialistas no processo de elaboração de suas políticas educacionais. Esta participação acaba sendo irrisória perto da massiva participação e poder de influência dos países centrais, normalmente membros orgânicos da própria organização. Assim, diante de vozes dissonantes na estrutura das ações da OCDE, acabam por prevalecer as proposições e a lógica de funcionamento das sociedades desenvolvidas economicamente. Por mais que os programas e projetos da OCDE adequem ou acrescentem propostas mais progressistas no tocante a políticas públicas educacionais, o interesse do capital acaba por readequar tudo aquilo que fere ou destoa da dinâmica histórica do movimento internacional do capital produtivo. Por vezes prevalecem as relações hierárquicas de dominação e recolonização intelectual.

Essa lógica de produção e disseminação internacional de proposições sobre as finalidades da educação conta com consentimento dos governos nacionais, empresários e partidos políticos. Conforme Shiroma, Campos e Garcia (2005), atua-se de forma contínua e visível, por meio da hegemonia discursiva, vocabulário e slogan que rompem as fronteiras e entram nos gabinetes do Governo Federal e secretários de educação em movimentos multidirecionais, pressionando por ajustes. Sedimenta-se, então, o fenômeno da globalização das políticas sociais (LEVIN, 1998). Sobressaem-se as ações dos outsiders, stakeholders, experts e economistas guardiões do capital interessados na Educação Básica, os reformadores empresariais da educação (FREITAS, 2011). Ainda que sob muitas resistências de associações científicas e movimentos sociais, as práticas neotecnicistas e neoliberais 
coexistem com outras na Educação Básica, que defendem a educação como um direito humano, social e subjetivo. E como essa influência ganha materialidade em um país como o Brasil? Observe-se, por exemplo, o Plano Nacional de Educação (PNE) 2014-24, Lei n 13.005/2014 (BRASIL, 2014), que prevê, como estratégia de mensuração da qualidade nacional da Educação Básica, objeto da meta $n^{\circ}$ 07, a utilização do PISA como referência, com projeções de desempenho discente para os ciclos avaliativos de 2015, 2018 e 2021 do programa da OCDE. Cabe registrar, também, as discussões e embates acerca da Base Nacional Curricular Comum (BNCC) para o Ensino Fundamental e para o Ensino Médio, em que fundamentos pedagógicos são buscados em conceitos disseminados pela OCDE, como a concepção de competência global (BRASIL, 2018). Por fim, a própria fundamentação técnica do Índice de Desenvolvimento da Educação Básica - IDEB toma, como referência, níveis médios de desempenho dos países da OCDE no PISA como norte de qualidade no longo prazo para a educação brasileira. Dito de outro modo, a influência externa não apenas chega aos gabinetes governamentais, mas se torna determinação legal!

\section{CONSIDERAÇÕES PARA CONTINUAR AS REFLEXÕES}

O projeto Educação 2030 da OCDE propõe uma bússola de aprendizagem para o bem-estar discente futuro. Argumenta-se que, "como um mapa, não se diz onde se deve ir, mas quais são as possibilidades", que se "pode permitir pensamentos divergentes, mostrar outros lugares, outras formas de se pensar" (SCHLEICHER, 2018). A finalidade admitida é a da passagem de um currículo estático e fragmentado para um currículo adaptável e dinâmico, o mais científico possível e de modo a refletir as demandas das sociedades modernas.

Contudo, ao transpormos a cortina dos discursos, revela-se o propósito de direcionar e guiar a aprendizagem para, em seguida, mensurar, quantificar e comparar o desempenho dos estudantes, dos países e entre os países, conforme critérios cuja definição perpassa parcelas restritas da 
sociedade. Forças internacionais voltadas à educação preconizam um currículo global escolar, uma padronização e commoditização do serviço educacional. Dos gabinetes internacionais, nas asas dos empresários e governos, os interesses pela educação alcançam a antessala das escolas e estão na porta das salas de aula.

Esse movimento, dinâmico e contraditório, faz-nos apreender os interesses visíveis dos empresários, stakeholders, experts, líderes e da OCDE ao assumirem e posicionarem a Educação Básica como nicho estratégico de exploração econômica e tecnológica. Preconizam que se vive atualmente (2018) uma luta entre humanos e tecnologias e não entre classes sociais. Oferecem-nos um mapa sem pontos cardeais, como um guia para a composição de currículos escolares adaptáveis e instrumentais. Definem-se as competências, conhecimento, habilidades, atitudes e valores a serem inseridos nos currículos nacionais e, em seguida, preparam-se os dados a serem utilizados para mensurar, quantificar e comparar os países. No entanto, os interesses invisíveis estão colocados ao apresentar o interesse particular da OCDE como se fosse universal. Ao negar a luta entre as classes sociais, obscurecem-se as determinações econômicas do capital que já se projeta para 2030. Nas palavras de Frigotto e Ferreira (2019, p. 92), ao se propor "igualar liberdade formal de escolha às condições desiguais reais na estrutura social, toma-se a meritocracia como sendo mérito individual". Escamoteiam-se as relações de poder e os dissensos, presumindo-se uma falsa neutralidade, na medida em que se ofuscam as estruturas econômicas geradoras de desigualdades sociais, em que se responsabiliza o indivíduoaluno como um ser ahistórico, isolado e abstrato, a enfrentar questões do modo de produção e da acumulação do capital ou a resignar-se, a competir e adaptar-se às circunstâncias das crises cíclicas do capital. Dissimulam-se as relações de poder e dissensos, mas supõe-se uma neutralidade e linearidade. O real disfarça-se em discursos e ações universais em busca da consolidação de interesses particulares ou de grupos. São tempos de flexibilidade, exacerbação da meritocracia, individualismo e 
competitividade geradores de injustiças sociais. Apressemos em retomar o caminho da democracia e dos direitos humanos e sociais. Urge!

Uma bússola é um instrumento de orientação geográfica para marinheiros e navegantes. Mas, paradoxalmente para as Ciências Sociais e, em específico, para a Educação, possuir uma agulha atraída por polo magnético significa excluir as múltiplas possibilidades de o ser humano conduzir-se, reinventar-se, decidir e buscar sua própria emancipação frente às determinações socioeconômicas históricas. Na Educação, o ser humano não aprende a utilizar a bússola para caminhar, mas aprende a caminhar para construir a sua própria bússola, sua história.

\section{REFERÊNCIAS}

ADRIÃO, T. Dimensões e formas da privatização da educação no Brasil: caracterização a partir de mapeamento de produções nacionais e internacionais. Currículo sem Fronteiras, v. 18, n. 1, p. 8-28, janeiro/abril. 2018.

ADRIÃO, T.; DOMICIANO, C. A. A Educação pública e as corporações: avanços e contradições em uma década de ampliação de investimento no BRASIL. Fineduca - Revista de Financiamento da Educação. Porto Alegre. Volume 8, n. 3, p. 1-18, 2018.

BRASIL. Ministério da Fazenda. Gabinete do Ministro. Portaria n 92 , de 12 de maio de 2003. Aprova a criação do Ponto de Contato Nacional segundo as Diretrizes para as Multinacionais - OCDE. Diário Oficial da União. Brasília, DF, 14 mai. 2003, Sessão 01, p.12.

BRASIL. Ministério da Fazenda. Gabinete do Ministro. Portaria interministerial $n^{\circ}$ 37, de 19 de fevereiro de 2013. Dispõe sobre a estrutura e organização do Ponto de Contato Nacional para as Diretrizes da Organização para Cooperação e Desenvolvimento Econômico (OCDE) para as Empresas Multinacionais. Diário Oficial da União. Brasília, DF, 20 fev. 2013, Sessão 01, p.42.

BRASIL. Ministério das Relações Exteriores. O Brasil e a OCDE. Disponível em: <http://www.itamaraty.gov.br/pt-BR/politica-externa/diplomacia-economicacomercial-e-financeira/15584-o-brasil-e-a-ocde>. Acesso em: 24 abr. 2019.

BRASIL. Ministério da Educação. Base Nacional Comum Curricular: Educação é a Base. 2018. Disponível em:

http://basenacionalcomum.mec.gov.br/abase. Acesso em: 05 mar. 2019. 
FARIA FILHO, L. M. de. A legislação escolar como fonte para a história da educação: uma tentativa de interpretação. In: FARIA FILHO, L. M. de. (Org). Educação, modernidade e civilização. Belo Horizonte: Autêntica, 1998, p. 89125.

FREIRE, P. Pedagogia da autonomia: saberes necessários à prática educativa. Coleção Leitura. São Paulo: Paz e Terra, 2002.

FREITAS, L. C. de. A qualidade da escola e os profissionais da educação: confiança nas relações ou cultura da auditoria. In: Cunha, C.; Souza, J. V. e Silva, M. A. (Org.). Políticas Públicas de Educação na América Latina: lições aprendidas e desafios. Campinas: Autores Associados, 201 1a, p. 279-302.

FREITAS, L. C. de. Educadores versus reformadores empresariais: a disputa pela agenda educacional. Revista APASE (São Paulo), v. XI, p. 14-18, 2012.

FREITAS, L. C. de. Os reformadores empresariais da educação: a consolidação do neotecnicismo no Brasil. In: Fontoura, H. A. (Org.). Políticas públicas e movimentos sociais. Rio de Janeiro: ANPED Sudeste, 2011 b, v. 3, p. 72-90.

FRIGOTTO, G.; FERREIRA, S. Cultura Autoritária, ultraconservadorismo, fundamentalismo religioso e o controle ideológico da educação básica. In: Trabalho Necessário, v.17, n 32, jan-abr, p. 88-113. 2019.

IASI, M. L. O método: as categorias fundantes no século XXI. In: Trabalho Necessário, v.17, n 32, jan-abr, p. 33-67. 2019.

LEVIN, B. An epidemic of education policy: (what) can we learn from each other? Comparative Education, Abingdon, v.34, n. 2, p. 131-141, 1998.

LIBANEO, J. C. O dualismo perverso da escola pública brasileira: escola do conhecimento para os ricos, escola do acolhimento social para os pobres. Educação e Pesquisa. São Paulo, v. 38, n. 1, p. 13-28, Mar. 2012.

ORGANISATION FOR ECONOMIC CO-OPERATION AND DEVELOPMENT (OECD). Definition and Selection of Competencies: Theoretical and Conceptual Foundations DeSeCo. 2001. Disponível em: <http://www.oecd.org/education/skills-beyond-school/41529556.pdf>. Acesso em: 01 mai. 2019.

ORGANISATION FOR ECONOMIC CO-OPERATION AND DEVELOPMENT (OECD). Future of education and skills. [Projeto]. Disponível em: <http://www.oecd.org/education/2030-project>. Acesso em: 01 mai. 2019.

ORGANISATION FOR ECONOMIC CO-OPERATION AND DEVELOPMENT (OECD). The definition and selection of key competences: executive 
summary. 2005. Disponível em: <https://www.oecd.org/pisa/35070367.pdf>. Acesso em: 01 mai. 2019.

ORGANISATION FOR ECONOMIC CO-OPERATION AND DEVELOPMENT (OECD). The future of education and skills - Education 2030: The future we want. Diretoria de Educação e Habilidades. Paris: OCDE, 2018a. Disponível em:

<https://www.oecd.org/education/2030/E2030\%20Position\%20Paper\%20/05.0 4.2018).pdf>. Acesso em: 12 dez. 2018.

ORGANISATION FOR ECONOMIC CO-OPERATION AND DEVELOPMENT (OECD). The Future of Education and Skills - Education 2030: What is OECD Education 2030. 2018b. Disponível em:

<https://www.oecd.org/education/school/Flyer-The-Future-of-Education-andSkills-Education-2030.pdf>. Acesso em: 12 dez. 2018.

PEREIRA, R. da S. A política de competências e habilidades na educação básica pública: relações entre Brasil e OCDE. 2016. 285 f., il. Tese UnB. Brasília. 2016.

SAVAGE, G. Neoliberalism, education and curriculum. In Powers of Curriculum: Sociological Perspectives on Education. South Melbourne, Vic.: Oxford University Press Australia and New Zealand. 2017. p. 143-165.

SCHLEICHER, A. Education for a better world - the OECD Learning Framework 2030. EduSkills OECD. Youtube. 2018. Disponível em:

<https://www.youtube.com/watch>. Acesso em: 10 mar. 2019.

SHIROMA, E.; CAMPOS, R. F.; GARCIA, R. M. Decifrar textos para compreender a política: subsídios teórico-metodológicos para análise de documentos.

Perspectiva. Florianópolis, v. 23, n. 2, p. 427-446, 2005.

UNESCO. Sustainable development goal 4: Ensure inclusive and equitable quality education and promote lifelong learning opportunities for all Disponível em: <https://sustainabledevelopment.un.org/sdg4\#targets>. Acesso em: 10 mar. 2019.

Recebido em: 13 de maio de 2019 Aprovado em: 02 de dezembro de 2019 